\title{
MEMBANGUN LITERASI MASYARAKAT DI KABUPATEN BOGOR
}

\author{
Riris Aishah Prasetyowati ${ }^{1}$, Khoerul Fahmi, Abu Bakar ${ }^{2}$ \\ riris@uika-bogor.ac.id \\ Dosen Fakultas Ekonomi ${ }^{1}$, Mahasiswa KKN Kelompok 5 Tahun $2017^{2}$
}

\begin{abstract}
ABSTRAK
Pendidikan di Perguruan Tinggi dilaksanakan dengan cara membekali dan mengembangkan religius, kecakapan, keterampilan, kepekaan dan kecintaan mahasiswa terhadap kehidupan umat manusia pada umumnya dan masyarakat Indonesia pada khususnya. Pembekalan dan pengembangan hal-hal tersebut terangkum dalam Tri Dharma Perguruan Tinggi yaitu Pendidikan dan Pengajaran, Penelitian, dan Pengabdian kepada Masyarakat. Dalam UndangUndang Republik Indonesia Nomor 20 Tahun 2003 tentang Sistem Pendidikan Nasional pada pasal 20 ayat 2 dinyatakan : "Perguruan tinggi berkewajiban menyelenggarakan pendidikan, penelitian, dan pengabdian masyarakat". Kuliah Kerja Nyata kelompok 05, mahasiswa Universitas Ibn Khaldun Bogor dilaksanakan di Jalan Suka Bakti Rt 02/Rw 07 Desa Cogreg Kecamatan Parung Kabupaten Bogor. mahasiswa melaksanakan program kerja yang di sesuaikan dengan potensi dan permasalahan. Alhamdulillah, program kerja yang telah di rencanakan telah terlaksana dengan baik, walaupun masih banyak yang harus di evaluasi. Salah satu program yaitu pembentukkan POSDAYA, yang di harapkan dapat menjadi wadah untuk warga. Kami harap dengan adanya KKN dapat memberikan motivasi dan membantu menghadirkan solusi dari masalah yang ada di Desa Cogreg yang menempatkan mahasiswa mahasiswa untuk mengabdikan diri dan memberikan manfaat kepada masyarakat sangatlah bagus, karena untuk membangun masyarakat bukan hanya tugas pemerintah akan tetapi tugas semua pihak, yang khususnya tugas mahasiswa sebagai agen perubahan kearah yang lebih baik.
\end{abstract}

Kata Kunci : KKN, Membangun, Program Kerja.

\section{PENDAHULUAN}

Jalan Suka Bakti adalah nama salah satu jalan yang ada di Desa Cogreg Kecamatan Parung Kabupaten Bogor, jalan Suka Bakti berada di RT 02 RW 07 Desa Cogreg. Sebagian penduduk berprofesi sebagai pedagang yang kebanyakan peternak ikan hias dan pembudi daya ikan lele.

Sarana dan prasarana yang ada di RW 07 cukup baik, terdapat 3 POSYANDU yang tersebar di beberapa
RT, masjid-masjid dan mushala, dan 1 Madrasah Ibtidaiyyah. Di RW 07 khususnya RT 02, masih sangat aman, walaupun pertahanan sipil ataupun petugas ronda tidak berjalan di RT 02 ini. Tapi Alhamdulillah, di RT 02 sangat aman dari tindakan-tindakan criminal seperti pencurian dan lain sebagainya.

Situasi prospektif pengembangan di desa Cogreg jalan Suka Bakti termasuk dalam perkembangan yang cukup maju. Hal ini dilihat dari aktifnya warga masyarakat yang selalu ikut serta dalam setiap kegiatan, juga adanya pemahaman 
mengenai keadaan Global saat ini sehingga sudah banyak penduduk yang sudah mengikuti arus globalisasi.

\section{Keadaan Geografis}

Desa Cogreg secara struktural merupakan bagian integral yang tak terpisahkan dari sistem perwilayahan Kecamatan Parung Kabupaten Bogor. Dengan luas wilayah 511,6Ha. Desa Cogreg adalah salah satu Desa dari 9 desa yang ada di Kecamatan Parung yaitu Desa Cogreg, Iwul, Jabon Mekar, Pamegar sari, Parung, Waru, Warujaya, Ciseeng, Bojong Indah, Bojong Sempu. Dan batas wilayahnya adalah sebagai berikut:

\begin{tabular}{|c|l|c|}
\hline No & Keterangan & Berbatasan \\
\hline 1 & Utara & $\begin{array}{c}\text { Desa Cibadung, Desa } \\
\text { Cibinong Kec. } \\
\text { Gunung Sindur }\end{array}$ \\
\hline 2 & Selatan & $\begin{array}{c}\text { Desa Bojong Indah } \\
\text { Desa Cihoe, Desa } \\
\text { Kuripan Kec. Ciseeng }\end{array}$ \\
\hline 3 & Barat & Desa Waru Jaya \\
\hline 4 & Timur & \\
\hline
\end{tabular}

Jumlah Penduduk

\begin{tabular}{|c|l|c|}
\hline No & Jenis Kelamin & Jumlah \\
\hline 1 & Laki-Laki & 8.339 \\
\hline 2 & Perempuan & 7.572 \\
\hline 3 & Kepala Keluarga & 3.909 \\
\hline \multicolumn{2}{|c|}{ Adapun dari aspek spiritualitas juga }
\end{tabular}

cukup bagus karena suasana religius yang masih kental di Desa ini, masih banyak pengajian-pengajian yang masih aktif yang rutin dilaksanakan setiap bualan, minggu, maupun setiap harinya. Untuk sarana dan prasarana Desa khususnya di RW 07 cukup lengkap antara lain seperti sarana peribadatan masjid dan mushola semuanya sudah ada dan sangat memadai.
Pendidikan

\begin{tabular}{|c|l|c|}
\hline No & Jenis Kelamin & Jumlah \\
\hline 1 & Pegawai Negeri Sipil & 124 \\
\hline 2 & TNI/Polri & 103 \\
\hline 3 & Wiraswasta/Pedagang & 1.172 \\
\hline
\end{tabular}

Dalam bidang Pendidikan di Desa Cogreg dapat dikatakan cukup bagus, karena pola fikir masyarakat yang sudah berkembang mengenai pendidikan yang mengakibatkan kesadaran mengenai pendidikan walaupun masih banyak masyarakat yang masih menjalankan pernikahan di usia dini. Dalam hal ini bisa di buktikan dari data umum Desa Cogreg mengenai kondisi pendidikan di Desa Cogreg yaitu terdapat 2.709 orang yang telah lulus dari sekolah umum dan 275 yang tidak sekolah, yang bisa di artikan di Desa Cogreg jumlah masyarakat yang melek akan pendidikan lebih banyak dari pada masyarakat yang belum melek pendidikan, walaupun jumlah masyarakat yang belum melek akan pendidikan cukup banyak. Adapun sarana dan prasarana penunjang dalam pendidikan sangat bagus, terdapat 3 buah PAUD, 5 SD dan 1 SMP. Jadi, bisa dikatakan tidak ada masalah dalam bidang pendidikan mengenai sarana dan prasarana.

\section{Mata Pencaharian}

\begin{tabular}{|c|l|c|}
\hline No & Jenis Kelamin & Jumlah \\
\hline 1 & Pegawai Negeri Sipil & 124 \\
\hline 2 & TNI/Polri & 103 \\
\hline 3 & Wiraswasta/Pedagang & 1.172 \\
\hline 4 & Petani & 781 \\
\hline 5 & Buruh tani & 586 \\
\hline 6 & Peternak & 195 \\
\hline 7 & Pensiunan & 34 \\
\hline 8 & Tidak Bekerja & 1.141 \\
\hline
\end{tabular}

penduduk setempat bekerja sebagai pedagang, dan banyak sekali masyarakat 
yang mengembang biakan ikan lele, oleh karena itu desa Cogreg menjadi salah satu daerah pemasok lele di kecamatan parung bahkan JABODETABEK. Di Jalan Suka Bhakti Desa Cogreg yang kami tinggali sebagian penduduk bermata pencaharian sebagai pengembang biak ikan lele. Di Desa Cogreg masih banyak yang tidak bekerja / pengangguran, jadi secara garis besar masyarakat Desa Cogreg masih dikatakan rata-rata dalam angka kemiskinan atau masih menengah kebawah.

\section{METODE PENGABDIAN}

Tahapan pelaksanaan pada kegiatan ini, dapat dilihat pada bagan dibawah ini:

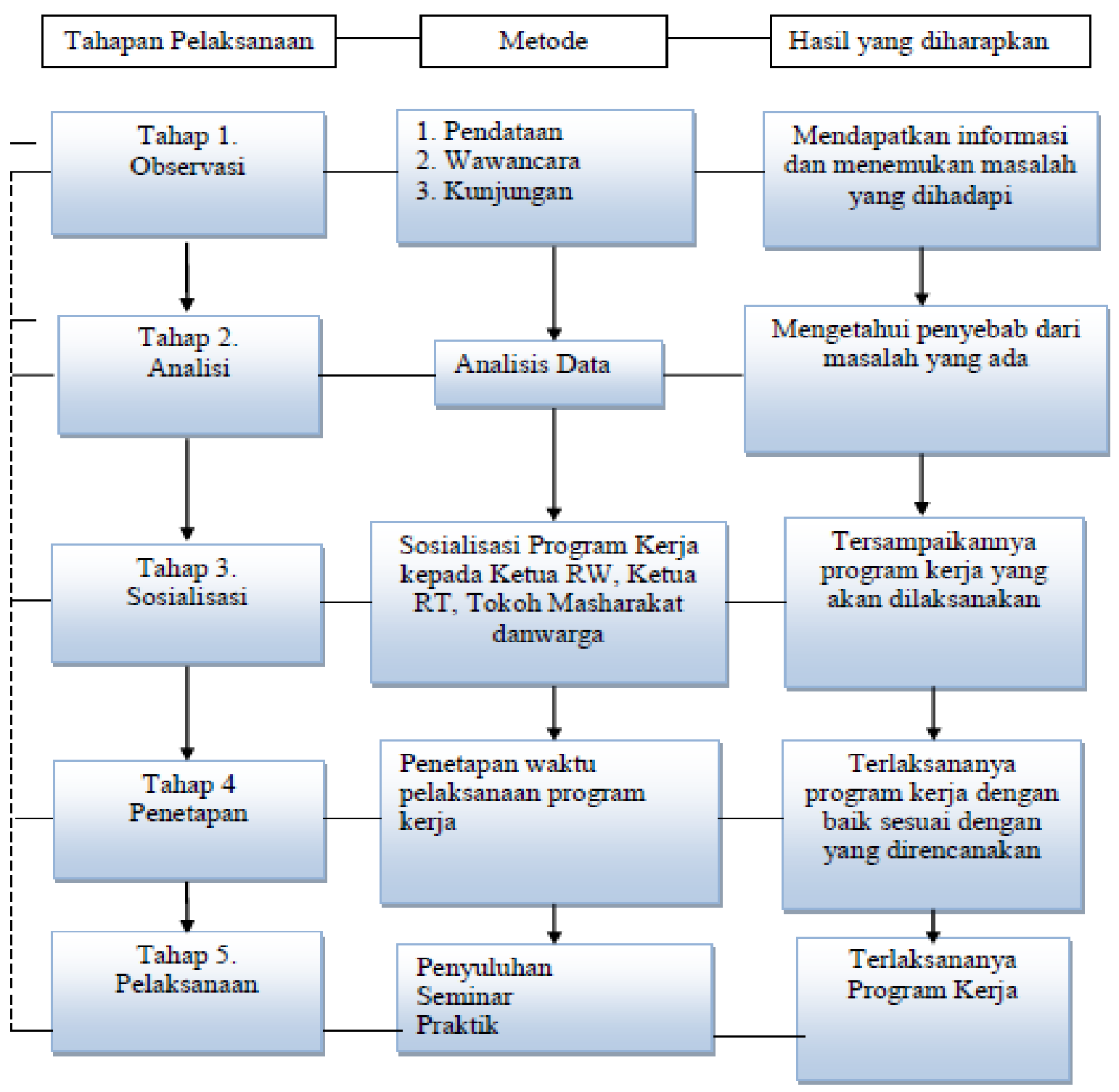


Jadwal Kegiatan

\begin{tabular}{|c|c|c|c|c|c|}
\hline \multirow{2}{*}{ No. } & \multirow{2}{*}{ Kegiatan } & \multicolumn{4}{|c|}{ Minggu } \\
\hline & & \begin{tabular}{l|l}
1 & 2
\end{tabular} & 3 & 4 & 5 \\
\hline \multicolumn{6}{|c|}{ Program Kelompok } \\
\hline 1 & Pembentukan POSDAYA & & & & \\
\hline 2 & Peringatan HUT RI & & & & \\
\hline 3 & Perpustakaan & & & & \\
\hline \multicolumn{6}{|c|}{ Program Per Bidang } \\
\hline 1 & KF (Keaksaraan Fungsional) & & & & \\
\hline 2 & Partisipasi mengajar di Sekolah & & & & \\
\hline 3 & Bimbel & & & & \\
\hline 4 & Kantin Kejujuran & & & & \\
\hline 5 & Kerajinan Tangan & & & & \\
\hline 6 & Demo Makanan & & & & \\
\hline 7 & Menumbuhkan Budaya Menabung & & & & \\
\hline 8 & Seminar Usaha Mikro & & & & \\
\hline 9 & Pengajian Bapak-Bapak & & & & \\
\hline 10 & Papan Nama Mushala & & & & \\
\hline 11 & Qurban & & & & \\
\hline 12 & Pendidikan Anak Usia Dini & & & & \\
\hline 13 & Tahsin Anak Usia Dini & & & & \\
\hline 14 & Pengajian Ibu-Ibu & & & & \\
\hline 15 & Pengajian Anak-anak & & & & \\
\hline 16 & Pengajian Pemudi & & & & \\
\hline 17 & Perilaku Hidup Bersih dan Sehat & & & & \\
\hline 18 & Periksa Kesehatan Gratis & & & & \\
\hline 19 & Seminar HPAI & & & & \\
\hline 20 & Penyuluhan Sikat Gigi & & & & \\
\hline 21 & Biopori & & & & \\
\hline 22 & Plang Nama Jalan & & & & \\
\hline 23 & Tiang Bendera & & & & \\
\hline 24 & Gapura & & & & \\
\hline 25 & Pengadaan Pohon & & & & \\
\hline 26 & Budi daya cacing & & & & \\
\hline
\end{tabular}

\section{Metode Pendekatan}

Pendekatan yang digunakan dalam kegiatan ini adalah:

1. Pendekatan religius, yaitu pendekatan yang menggunakan nilai-nilai agama sebagai basis kegiatan. Pendekatan ini sangat penting karena permasalahan pemahaman radikalisme dalam masyarakat sangat dipengaruhi oleh faktor keimanan, pengalaman keagamaan, rasa tanggungjawab dan pengetahuan (Rachmawati, 2010).
2. Pendekatan organisasi, yaitu pendekatan dimana seluruh kegiatan diorganisir oleh Pondok Pesantren As Salaam dan SMP al-Ittihadiyyah. Hal ini sesuai dengan hasil penelitian Bahari (2010) dimana dia menemukan bahwa keterlibatan organisasi mempunyai pengaruh langsung terhadap toleransi.

3. Pendekatan kekerabatan, artinya bahwa pembinaan yang dilakukan senantiasa dikaitkan dalam rangka membangun kekerabatan antar jama'ah yang semakin memudar. Nurhayati (2005) 
menemukan bahwa faktor pendukung toleransi umat Islam dengan Hindu adalah adanya sistem kekerabatan.

4. Pendekatan berdasarkan karakter masyarakat, yakni pembinaan yang dilakukan akan disesuaikan dengan karakter masyarakat. Joyce dan Weil (1996) mengungkapkan bahwa model pendidikan yang relevan dengan perilaku sosial dan nilai adalah dengan banyak memberikan permainan peran. Hal ini dilakukan untuk memberi pengalaman riil kepada peserta didik tentang sesuatu yang dilakukan atau dirasakan oleh orang lain. Memang, dalam prakteknya, tidak seluruh aspek harus menggunakan permainan ini. Dalam beberapa hal, terdapat kegiatankegiatan yang hanya golongan tertentu untuk melakukannya. Sejalan dengan konsep Joyce dan Weil, cooperative learning yang digagas Slavin (2005) dapat digunakan untuk membangun kesadaran toleransi masyarakat. Hal ini karena penekanan dari konsep pendidikan ini adalah kerjasama yang merupakan urat nadi toleransi. Dengan demikian, model pendidikan yang akan dibangun menggunakan dua konsep utama yaitu role playing model dan cooperative learning model.

\section{Partisipasi Masyarakat dalam Pelaksanaan Program}

Partisipasi masyarakat yang dilakukan dalam kegiatan ini adalah sebagai berikut:

1. Mempersiapkan jama'ah yang bersedia mengikuti kegiatan-kegiatan yang akan dilaksanakan.

2. Mempersiapkan tempat untuk penyuluhan.

3. Membantu mengumpulkan warga masyarakat untuk program cek kesehatan serta ikut serta dalam program tersebut.

4. Pelaksana kegiatan pembinaan.

5. Bersama-sama dengan Tim Pengusul melakukan monitoring pelaksanaan pembinaan dan pelatihan.

\section{Langkah Evaluasi}

Evaluasi yang akan dilakukan terdiri dari:

1. Evaluasi proses, yang terkait dengan perencanaan, pelaksanaan dan monitoring kegiatan. Evaluasi proses akan dilakukan setiap pekan bersama dengan masyarakat.

2. Evaluasi hasil, yang akan dilaksanakan setelah kegiatan dilaksanakan. Evaluasi hasil ditujukan untuk menguji pemahaman jama'ah tentang radikalisme dengan target capaian $100 \%$ tidak radikal. Selain itu, evaluasi hasil akan ditujukan pada peningkatan pendapatan jama'ah dengan target $80 \%$ jama'ah meningkat pendapatannya.

3. Evaluasi dampak, yang akan dilakukan 6 (enam) bulan setelah pelaksanaan pembinaan. Evaluasi dampak diarahkan untuk melihat efektivitas model pembinaan dan keberlangsungan industri rumah tangga (Gall dan Borg, 2003). 


\section{REALISASI PROGRAM}

\section{Program Bidang Pendidikan}

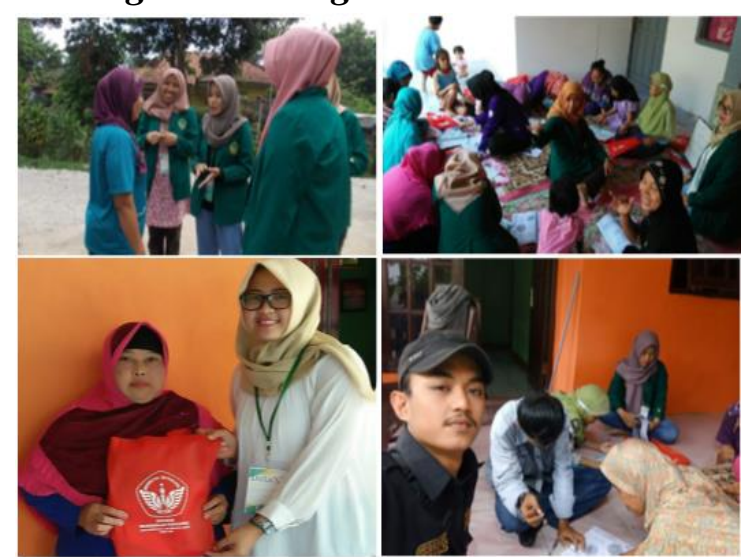

a. KF (Keaksaraan Fungsional)

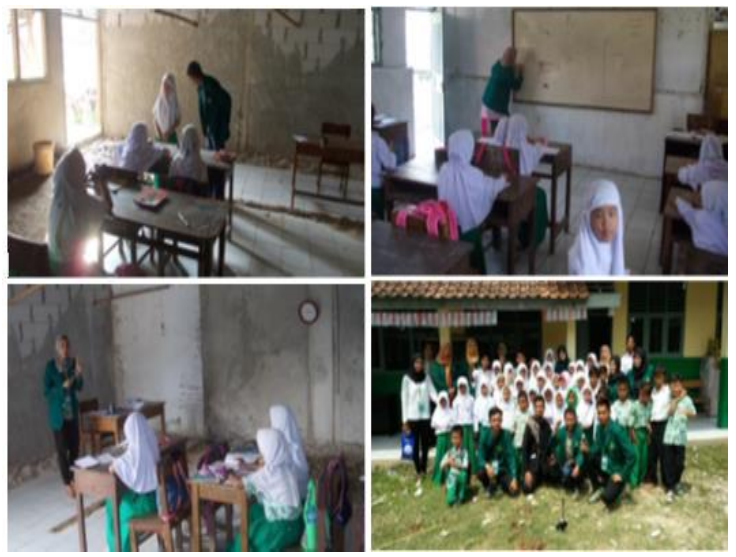

b. Partisipasi mengajar di Sekolah
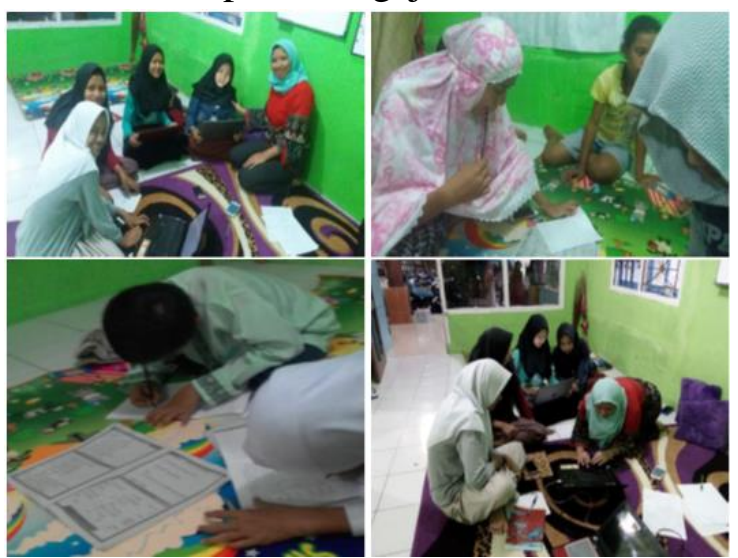

c. Bimbel

Tujuan : Agar masyarakat melek aksara, khususnya pada usia tua. Serta agar ilmu yang kita miliki bisa bermanfaat bagi warga sekitar, dan warga menjdapat manfaat dari apa yang telah di berikn atau di ajarkan.

\section{Program Bidang Lingkungan}

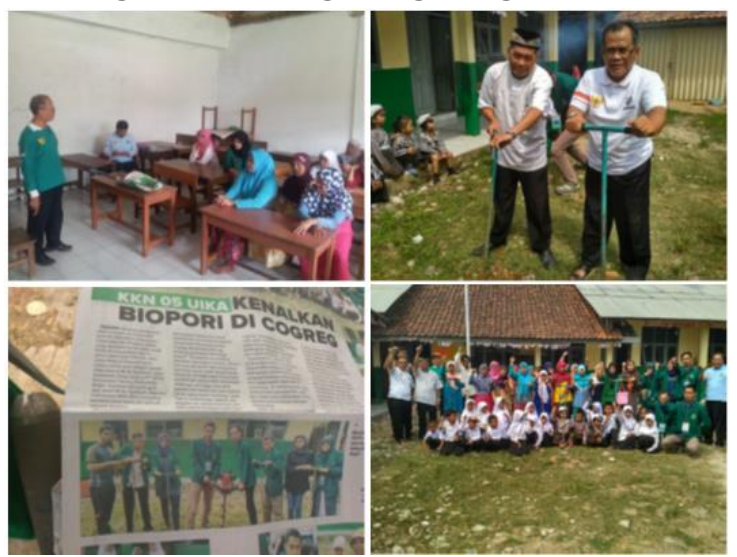

a. Biopori

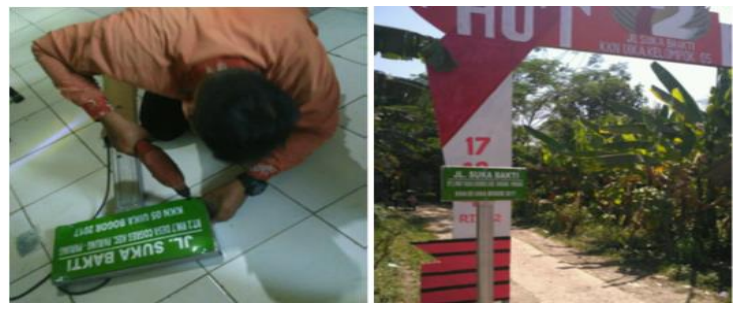

b. Plang Nama Jalan

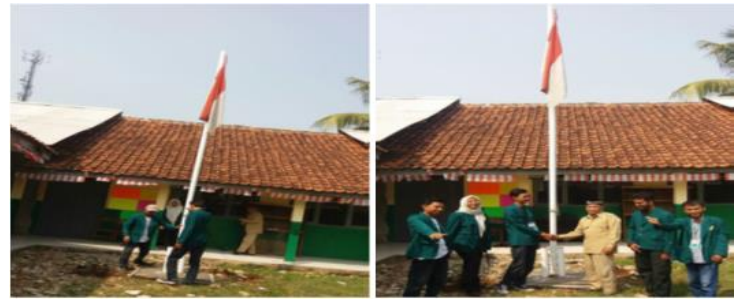

c. Tiang bendera

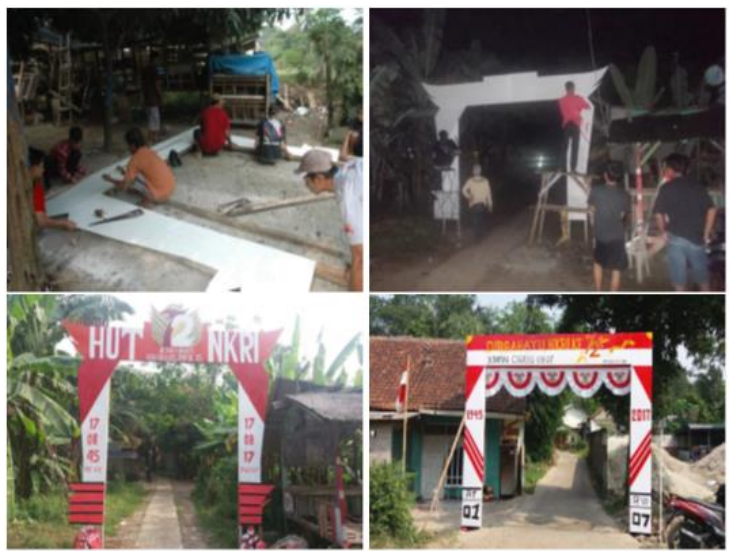

d. Gapura

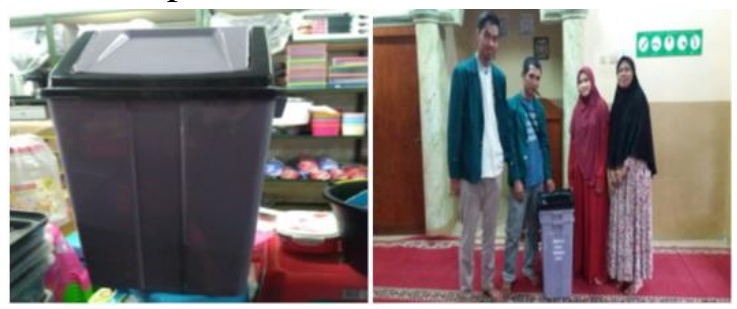

e. Pengadaan tempat sampah

f. Penanaman Pohon 
g. Budi daya cacing

Tujuan : Agar masyarakat dapat mengetahui mengenai BIOPORI, pentingnya keberadaan pohon-pohon di lingkungan kita, menyadari bahwa kebersihan itu suatu kebutuhan kita dan memmfasilitasi apa yang di butuhkan.

\section{Program Bidang Ekonomi}

a. Kantin Kejujuran

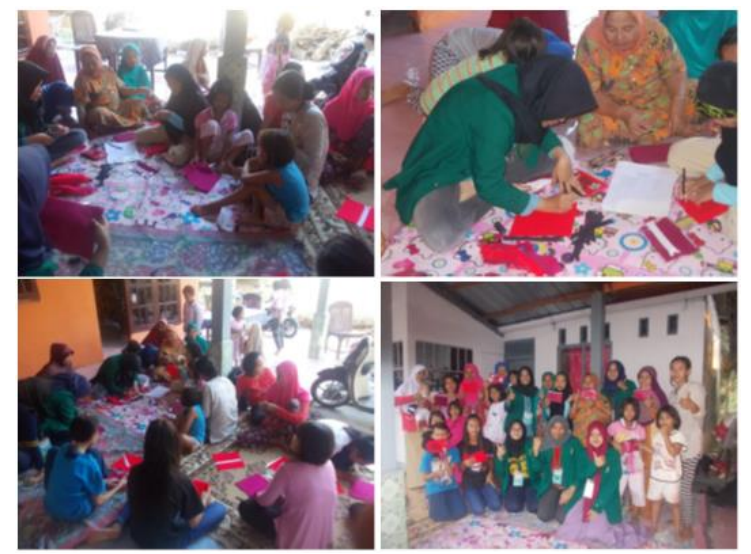

b. Kerajinan tangan

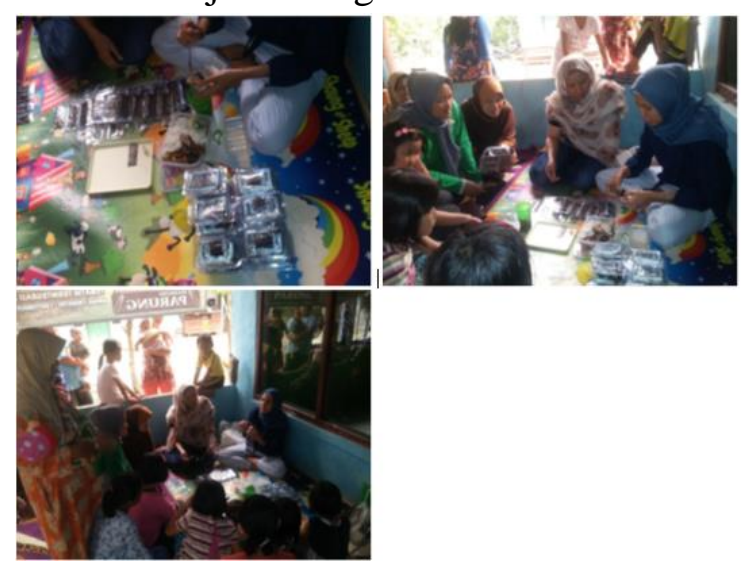

c. Demo Makanan (membuat Sushi Lele)

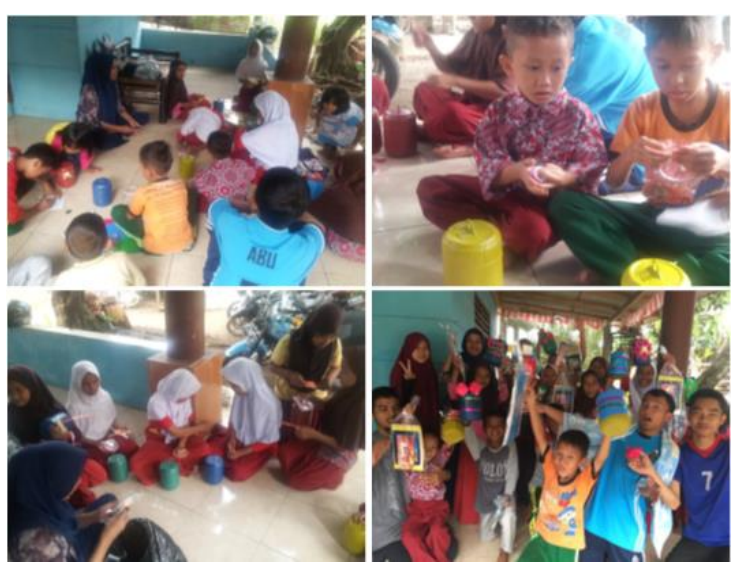

d. Menumbuhkan Budaya Menabung melalui Menghias Celengan

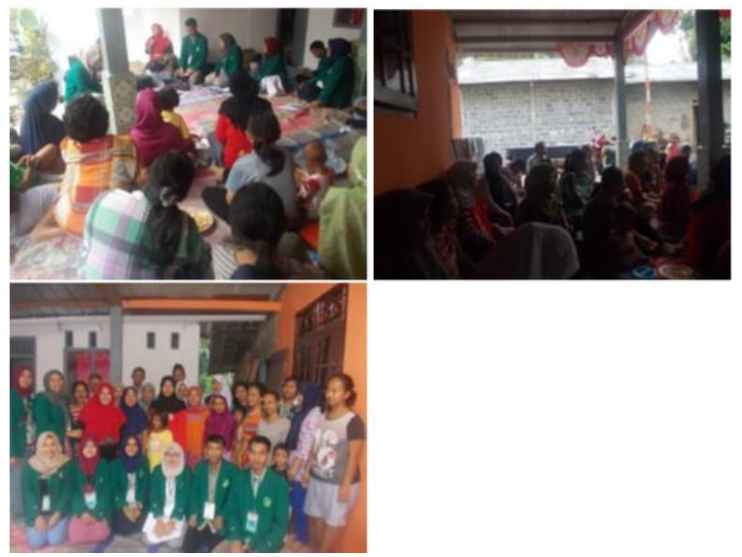

e. Seminar Usaha Mikro

Tujuan : Agar masyarakat memliki keterampilan dan bisa lebih berinovasi dalam menjalankan usaha dari keterampilan yang di miliki dan dari keelbihan yang ada pada lingkungannya atau kondisi yang ada di lingkungannya. Serta mengetahui ilmu mengenai usaha mikro sehingga ketika masyarakan memiliki suatu usaha bisa lebih produktif. 


\section{Program Bidang Kesehatan}

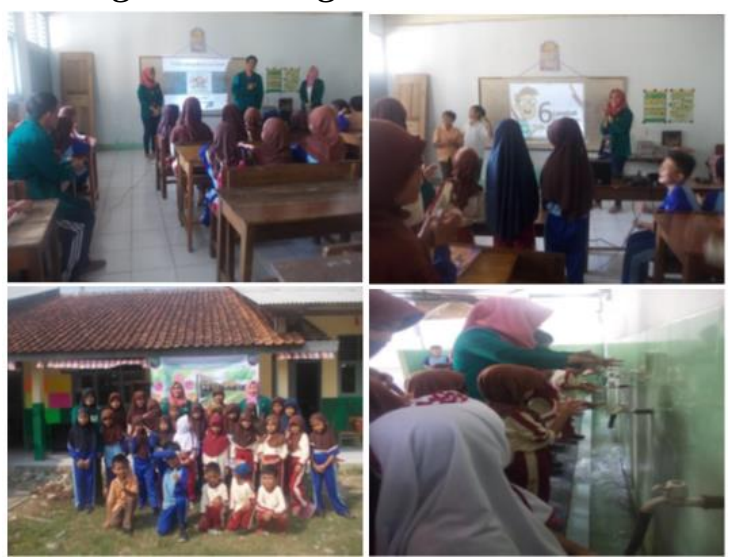

a. PHBS (Perilaku Hidup Sehat dan Bersih)

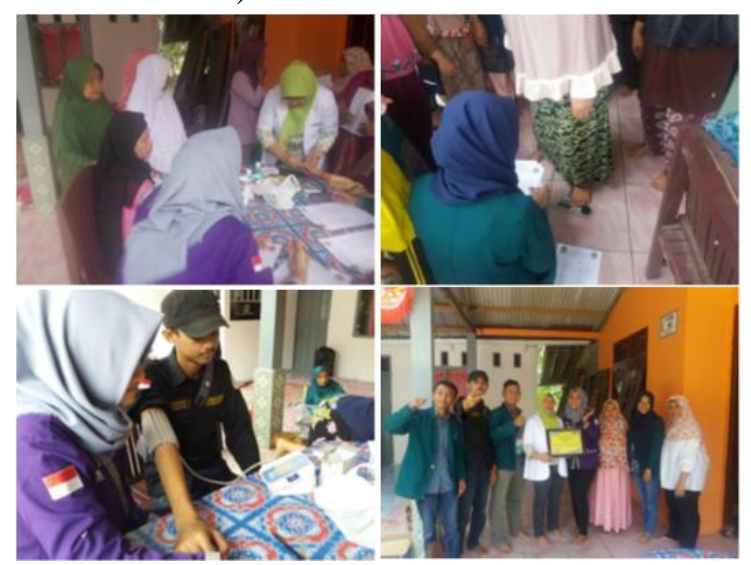

b. Pemeriksaan kesehatan gratis untuk masyarakat
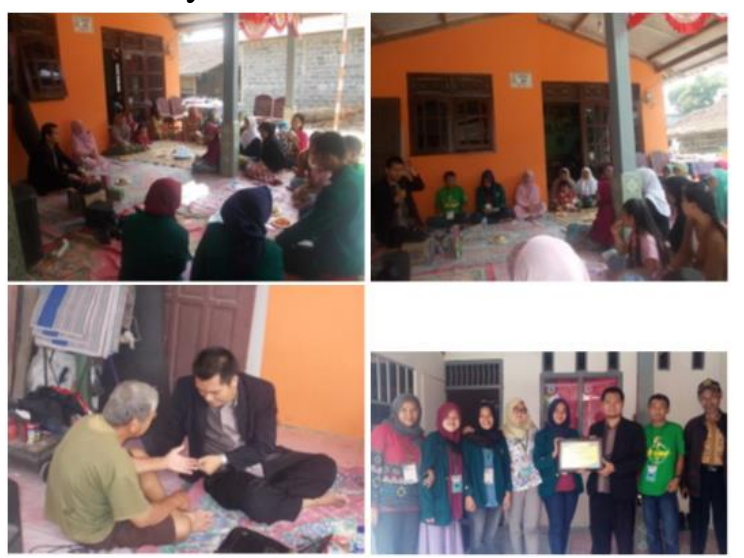

c. Seminar HPAI (Herbal Penawar AlWahidah Indonesia)

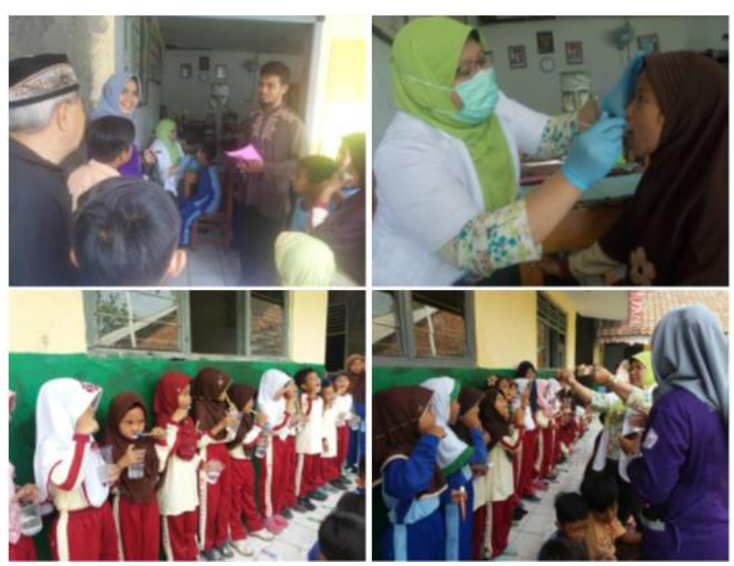

d. Penyuluhan Sikat Gigi yang baik dan benar

Tujuan : Agar masyarakat memiliki pola hidup bersih dan sehat, menyadari akan pentingnya kesehatan dan bagaimana menjaganya, serta mengetahui mengenai Herbal yang tak banyak orang konsumsi.

\section{Program Bidang Agama}

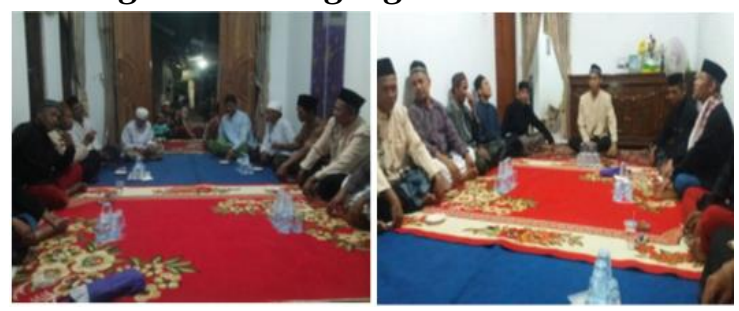

a. Pengajian Bapak-bapak

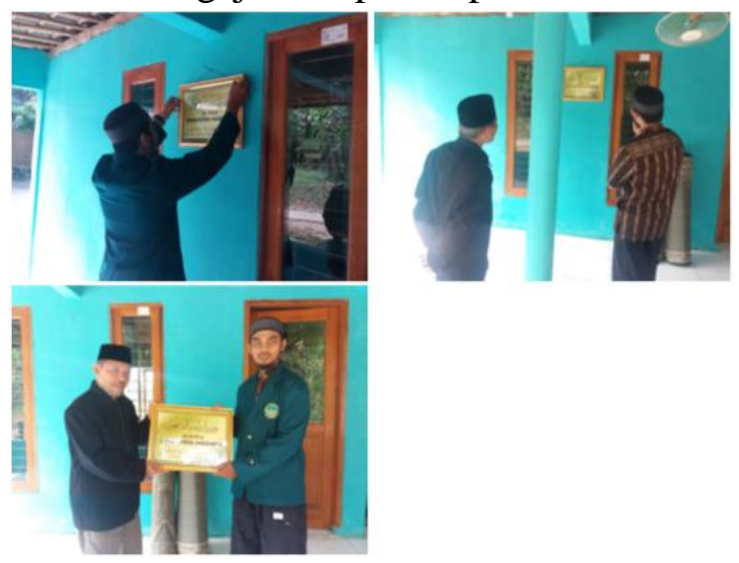

b. Papan Nama Mushala 


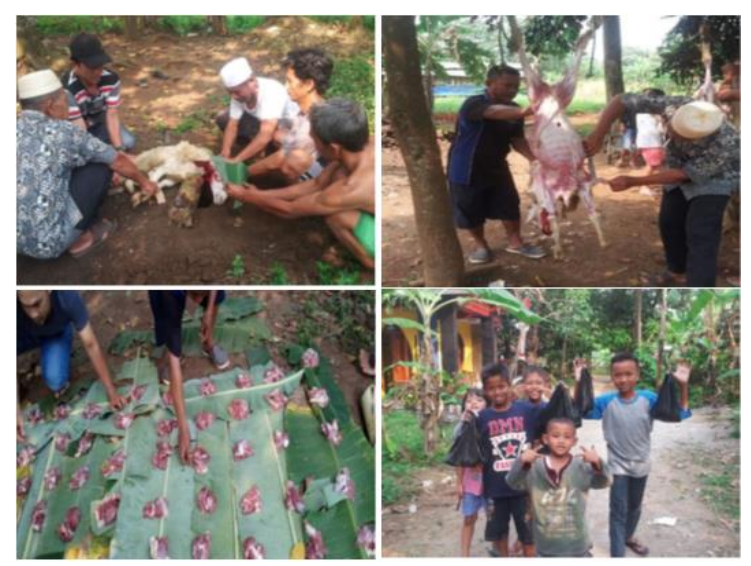

c. Qurban

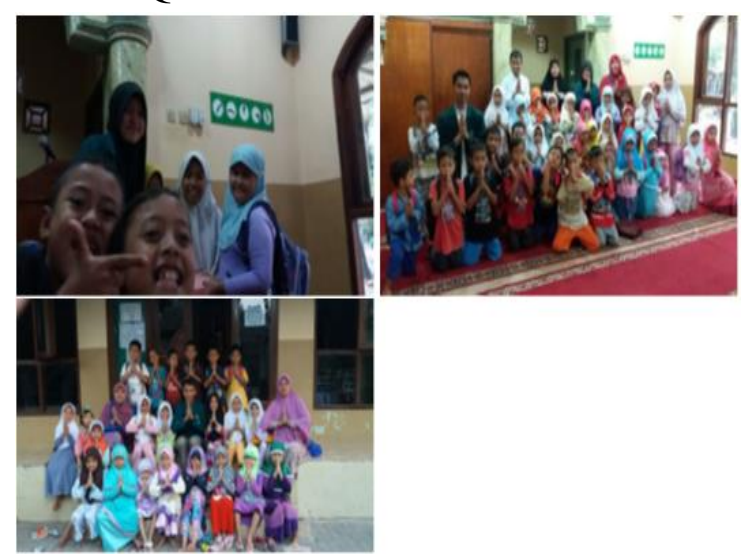

d. PAUD

e. TAUD
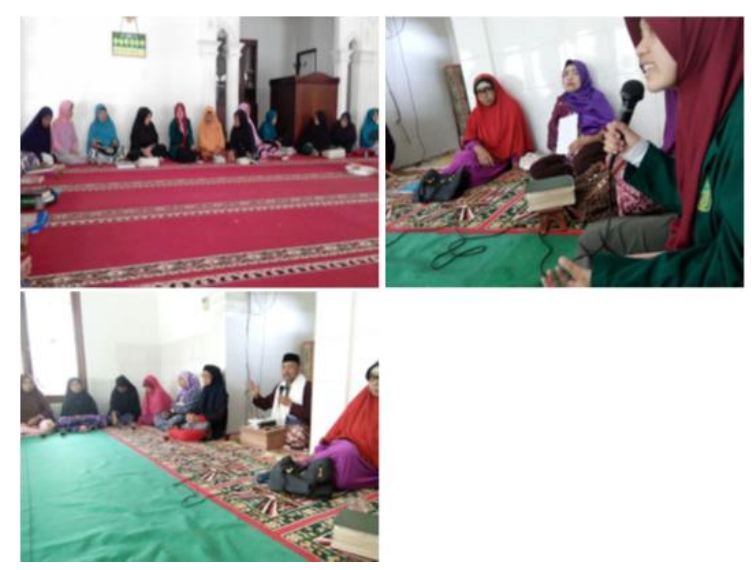

f. Pengajian Ibu-ibu

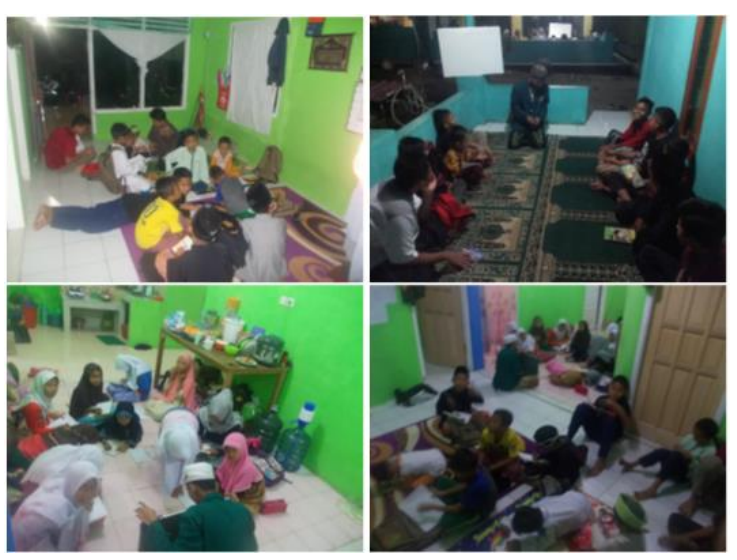

g. Pengajian Anak-anak

h. Pengajian Pemudi

Tujuan : Agar ilmu yang telah mahasiswa dapatkan baik selama belajar saat perkuliahan ataupun di luar perkuliahan dapat bermanfaat untuk masyarakat sekitar, serta masyarakat sekita dapat mengetahui ilmu-ilmu yang khususnya ilmu Agama.

\section{Kegiatan Lain-Lain}

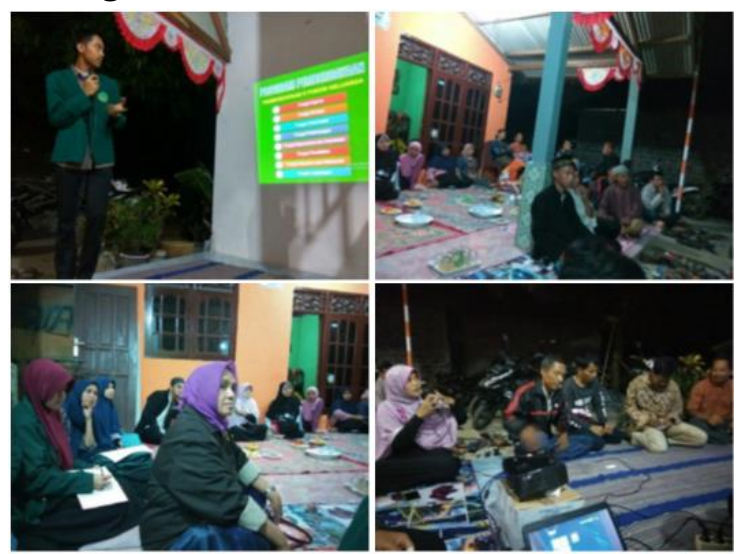

a. Pembentukan POSDAYA

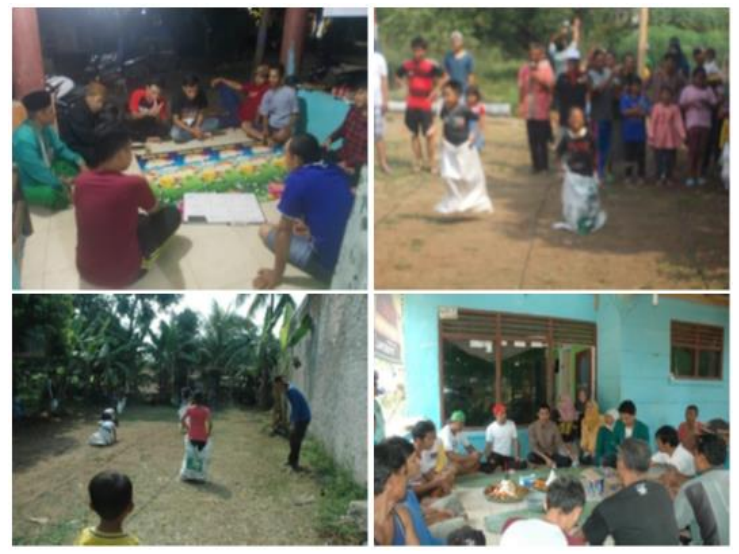

b. Peringatan HUT RI 

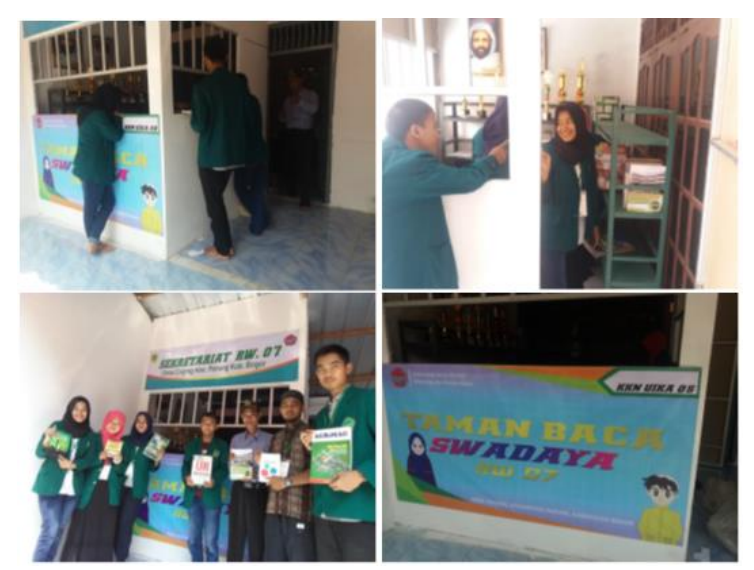

c. Taman Baca

\section{KESIMPULAN}

KKN Tematik Terintegrasi merupakan salah satu kegiatan yang memberikan peluang kepada para mahasiswa agar mempunyai pengalaman dalam Praktek lapangan diantaranya mengelola dana, wawasan dalam mengabdi di masyarakat, sehingga banyak hal-hal baru yang diperoleh. Tak hanya itu mahasiswa juga dapat merealisasikan rasa ingin tahunya, mereka melalui prosedur yang sistematis, yaitu dengan melakukan observasi, identifikasi masalah, cara menanggulangi masalah, merumuskan program, realisasi program, evaluasi dan penyusunan laporan program.

Kuliah kerja nyata (KKN) yang telah dilaksanakan di Desa Cogreg Kecamatan Parung Kabupaten Bogor Rw. 07 Rt 02 selama 32 hari sejak 07 Agustus 2017 sampai 07 september 2017, Alhamdulillah mendapat sambutan yang antusias dari warga sekitar.

Dengan program-program yang kami rencanakan dibuat semenarik mungkin dan sesuai dengan kondisi lingkungan yang ada sehingga dapat berjalan dan mendapat dukungan baik dari masyarakat. Berkat kerjasama yang solid antar anggota kelompok, Dosen pembimbing lapangan kami dan bantuan dari masyarakat, hambatan dan kendala yang terjadi, dapat kami atasi dengan baik. Ini dikarenakan kegiatan KKN adalah kegiatan kelompok, bukan kegiatan Individual. Berikut kami sampaikan kegiatan-kegiatan yang kami telah jalankan 


\section{REFERENSI}

Administrasi Profil Desa Cibitung Tengah

Bahari. (2010). Toleransi Beragama Mahasiswa (Studi tentang Pengaruh Kepribadian, Keterlibatan Organisasi, Hasil Belajar Pendidikan Agama, dan Lingkungan Pendidikan terhadap Toleransi Mahasiswa Berbeda Agama pada 7 Perguruan Tinggi Umum Negeri. Jakarta: Kementerian Agama RI Badan Litbang dan Diklat Puslitbang Kehidupan Keagamaan.

Joyce, Bruce dan Weil, Marsha. (1996). Models of Teaching. Boston: Allyn and Bacon

Nurhayati (2005) menemukan bahwa faktor pendukung toleransi umat

Petunjuk Pelaksanaan KKN Tematik Terintegrasi 2017 Universitas Ibn Khaldun Bogor

Rachmawati, AFD. (2006). Toleransi Antar Umat Islam dan Katolik: Studi Kasus di Dukuh Kasaran, Desa Pasungan, Kecamatan Ceper, Kabupaten Klaten. Skripsi. Semarang: IAIN Walisongo.

Slavin, R.E. (2005). Cooperative learning: theory, research and practice. London: Allyn and Bacon. 